\section{The role of proprioceptive stimulus change in the rat's avoidance learning}

\author{
FRED A. MASTERSON and MARY C. WHIPPLE \\ University of Delaware, Newark, Del. 19711 \\ and \\ SUSAN BENNER* \\ Wildwood High School, Wildwood, N.J. 08260
}

Barpress avoidance responses produce little change in proprioceptive feedback and are extremely difficult for rats to learn. In contrast, avoidance responses, such as running to a safe place, produce a large change in proprioceptive feedback and are learned very rapidly. On the basis of these findings, Meyer Cho, \& Wesemann (1960) proposed that the reinforcement for avoidance learning might come from the change in proprioceptive feedback provided by the avoidance response. Contrary to this hypothesis, the rats in the present experiment had great difficulty in learning to avoid shock by jumping, a response which produces a large change in proprioceptive feedback.

Over 10 years ago, Meyer, Cho, \& Wesemann (1960) were surprised to find that rats had great difficulty in learning a barpress avoidance response. Since each avoidance barpress was immediately followed by offset of a warning signal, Meyer et al concluded that warning signal offset was not an effective reward for rat avoidance behavior.

Instead, they hypothesized that the most important component of reward consisted of a large change in proprioceptive stimuli away from those which had been paired with shock. Since rats generally freeze on nonavoidance trials, it would follow that effective reward entails a large change in proprioceptive stimuli away from those produced by immobility. Barpress avoidance responses are difficult to learn because they do not produce a large change of this type. Conversely, highly active responses such as running or jumping should be learned rapidly since they produce proprioceptive stimuli which are considerably different from those associated with freezing.

It is well known that running is rapidly acquired by the rat as an avoidance response. While this supports the hypothesis of Meyer et al, it is also in accordance with Masterson's (1970) hypothesis that effective reward for the rat's avoidance behavior involves some of the stimulus changes associated with moving to a different spatial location. Therefore, a more rigorous test of the Meyer et al hypothesis would examine a highly active response which does not result in a net change in the rat's location.

*The third author was a participant in the NSF High School Summer Research Program at the University of Delaware (NSF Grant No. 6W-6618).
Jumping is such a response. The results of Mowrer \& Lamoreaux (1946) suggest that jumping can be acquired fairly rapidly. However, Bolles \& Tuttle (1967) commented that they were unable to replicate Mowrer and Lamoreaux's results in a pilot experiment. In particular, Bolles and Tuttle's pilot rats failed to learn to jump into the air to avoid shock. would be desirable to reexamine simple jumping as an avoidance response.

In addition to measuring how fast rats learn a jumping response to avoid shock, it is important to determine the extent to which the learning is actually due to an avoidance contingency. D'Amato (1967) measured a substantial number of preshock responses in a barpress escape learning situation even though no avoidance contingency was operating. In avoidance learning, the occurrence of such anticipatory escape responses may appear to be due to the avoidance contingency, and may lead to an in appropriately high estimate of learning. For this reason, a suitable control group is one for which the avoidance contingency is eliminated.

$$
\text { SUBJECTS }
$$

The Ss were 16 male Wistar rats, 90-100 days old.

\section{APPARATUS}

The apparatus was a Scientific Prototype A-100 rat chamber. The grid floor consisted of $1 / 8$-in. stainless steel rods spaced 9/16 in. center-to-center. The walls were extended 25 in. in height with heavy cardboard. Seams where the cardboard sections touched each other or touched the chamber were joined with masking tape. The extension of the walls permitted the rat to jump without allowing it to escape. The top of the apparatus was open. Given these conflicting results, it
The WS was a clicking sound provided by a pair of Telephonics Type TH37 earphones connected through a series resistor to a Foringer Model $1699 \mathrm{M} 1$ pulse stream generator (10 pulses/sec). The earphones were centered under the grid floor. The WS average level was $71.5 \mathrm{~dB}$, as measured inside the compartment with a General Radio 1551-C sound level meter (set on the B scale). The electric shock stimulus was obtained from a 150-K-ohm fixed impedance source (Campbell \& Masterson, 1969). The scrambler, contained in a Grason-Stadler Model E60708 shock generator, was used to vary the grid polarity pattern. One side of the shock source was wired to the front and rear metal walls of the shock chamber. The bar was insulated from the front wall. PROCEDURE

At the start of each training session, an $\mathrm{S}$ was lowered into the apparatus through the opening at the top. The first trial becan immediately. Each trial began with WS onset. A rat in Group A-E (avoid-escape) could avoid shock and terminate the WS by performing a jumping response within $10 \mathrm{sec}$ of WS onset. Otherwise, shock joined the WS 10 sec after WS onset and the rat could then escape the shock and terminate the WS by jumping. A rat in Group $\mathbf{E}$ (escape) could not avoid shock. For a rat in Group E, shock always joined the WS 10 sec after WS onset, at which time the rat could escape the shock and terminate the WS by jumping. A jump response was defined as any behavior causing all four of the rat's paws to rise above the floor simultaneously. In practice, instances of jumps were easily distinguished. A new trial began 60 sec after the preceding escape or avoidance response.

Five sessions of 30 trials each were run on consecutive days. On the first day, the shock level was initially set at $90 \mathrm{~V}$ and was then increased in order to elicit enough activity to permit shaping the jumping response. The average shock level for the first day was $115 \mathrm{~V}$. On the following days, the shock was set at $150 \mathrm{~V}$. Five of the Ss in Group E stopped jumping to escape this shock intensity, and for these five Ss the level was increased to $200 \mathrm{~V}$. For three of the five Ss, the level had to be additionally increased to $250 \mathrm{~V}$.

An average of 2.5 shaping trials was required for each $S$ at the beginning of the first day. No further shaping was required for Group A-E Ss. In contrast, every Group E $S$ required at least two more shaping trials during Days 2-5, and the average Group E S required about 1.5 on each of these days. These extra shaping trials were administered after the occurrence of unusually long escape latencies. 


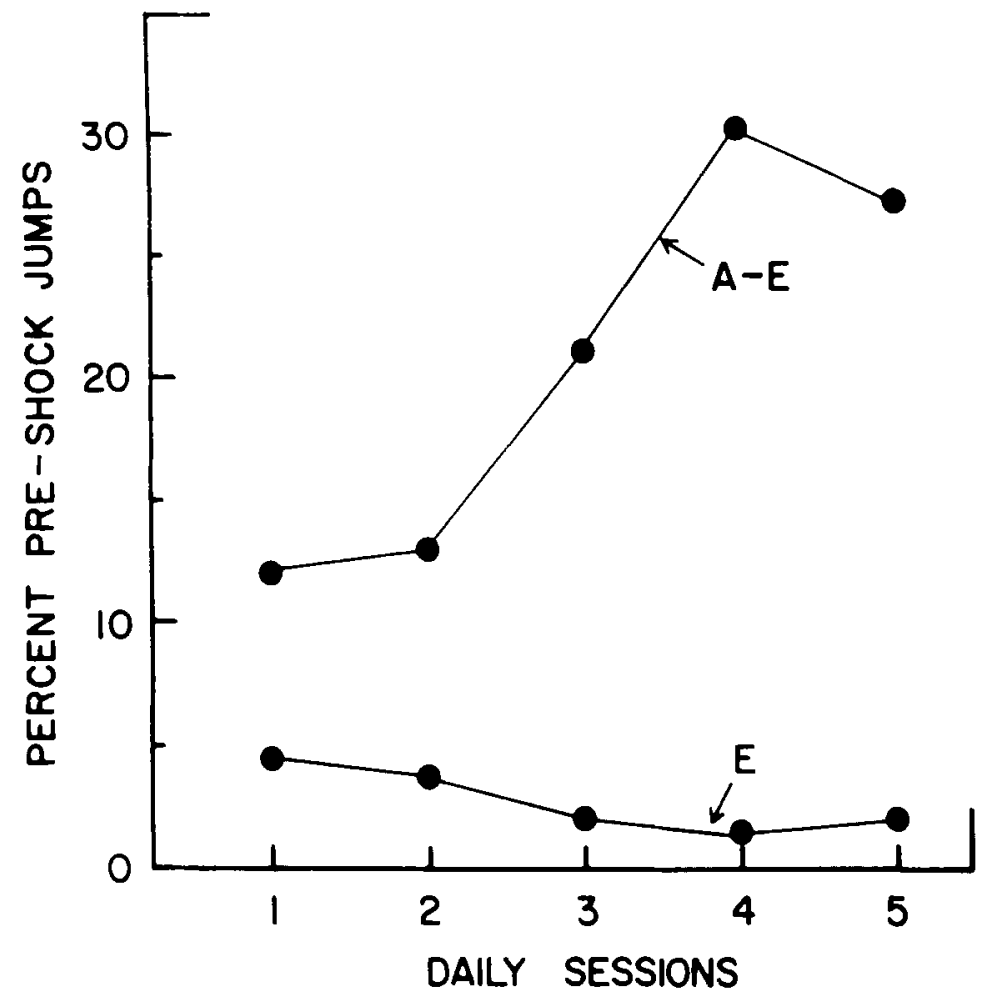

Fig. 1. Mean percentage of WS-shock intervals during which jumping occurred.

\section{RESULTS AND DISCUSSION}

The results refute the Meyer et al hypothesis. The rats in Group A-E could avoid shock by jumping-a behavior which should cause a large change in proprioceptive stimulation from that associated with shock. Yet, as Fig. 1 shows, the mean percent avoidance for the Group A-E rats was a mere $30 \%$ after 150 trials. Furthermore, there is some indication from the shape of the learning curve that this $30 \%$ performance was nearly asymptotic. In terms of individual performances, two rats scored between $0 \%$ and $19 \%$ avoidances over the last two sessions, four rats scored between $20 \%$ and $30 \%$, and two rats scored between $40 \%$ and $59 \%$. Thus, no $S$ performed at a high level, and most of the Ss' performances were quite mediocre. Unfortunately, exact measures of the vigor of the jumping responses were not obtained, so it is impossible to say whether a rat's avoidance performance and his response vigor were positively related (as would be predicted from the Meyer et al hypothesis).

It is interesting to note that the performance of the A-E rats is similar to the barpress avoidance performance of rats run under similar stimulus conditions (Masterson, 1970). Since a barpress response produces a relatively small change in proprioceptive stimulation, at least in comparison with jumping, it may be concluded that the amount of change in proprioceptive stimulation is not a crucial source of reward for the rat's avoidance behavior.

Although the performance of the rats in Group A-E was modest, it cannot be attributed to anticipatory escape responding. The rats in Group E, which could escape but could not avoid, performed virtually $0 \%$ preshock jumps across the five sessions. Comparing the two groups, the A-E rats jumped during significantly more of the WS-shock intervals than did the $E$ rats $(U=2.62$, $\mathrm{p}<.01)$. This finding contrasts with D'Amato's finding that rats performed anticipatory escape responses during $30 \%$ of the WS-shock intervals, even though there was no avoidance reinforcement contingency. D'Amato's use of discontinuous shock may have been a factor in raising the level of anticipatory responses. It would seem unlikely that the higher shock intensities used for some of the Group E rats can account for the extremely low overall performance of Group E. For one thing, these rats performed no more poorly than did the other Group $\mathrm{E}$ rats which received the same shock level as did the Group A-E rats. Nor can the additional shaping required for all of the rats in Group E account for the low performance of the Group $E$ rats. If anything, shaping should facilitate performance.
The present results, like the pilot results of Bolles \& Tuttle (1967), conflict with the findings of Mowrer \& Lamoreaux (1946). This conflict may be due to discrepancies between the exact criteria used in each experiment to define the jumping response. For example, Mowrer and Lamoreaux's definition of "jump" may have included the response of leaping across a relatively large area of the grid floor, a response which produces some of the stimulus consequences of spatial escape. It is also possible that Mowrer and Lamoreaux's rats ran forward immediately after each jump and thus learned a jump-run chain as a (partially superstitious) avoidance response. In the present study, the small floor area of the apparatus prevented horizontal leaping and running. Only jumps which did not produce a significant permanent change in the rat's position were possible.

The results for Group A-E add some additional support to Masterson's (1970) hypothesis that some subset of the proprioceptive feedback associated with moving to a different spatial location is essential for the effective reward of avoidance behaviors in the rat. An enlightening comparison can be made between the jumping response used in the present experiment, which does not produce a net change in spatial location, and the ledge jumping response used by Maatsch (1959), which does produce such a change. While the present rats performed poorly even after 150 trials, Maatsch's rats readily learned to jump to a ledge outside the shock box.

The Meyer et al hypothesis offered the first serious dissention from the hypothesis that WS offset was an important contributor to the reinforcement of avoidance behaviors in the rat. Meyer et al called attention to the importance of proprioceptive stimulus changes in providing effective reinforcement. The present results suggest that only certain types of proprioceptive stimulus changes are effective reinforcers. The proprioceptive stimuli associated with moving to a different spatial location appear to be particularly important.

\section{REFERENCES}

BOLLES, R. C., \& TUTTLE, A.V. A failure to reinforce instrumental behavior by terminating a stimulus that had been paired with shock. Psychonomic Science, 1967, 9, 255-256.

CAMPBELL, B. A., \& MASTERSON, F. A. Psychophysics of punishment. In $B$. A. Campbell and R. M. Church (Eds.). Punishment and aversive behavior. New York: A ppleton-Century-Crofts, 1969.

D'AMATO, M. R. Role of anticipatory responses in avoidance conditioning: An important control. Psychonomic Science. 1967, 8, 191-192. 
MAATSCH, J. L. Learning and fixation after a single shock trial. Journal of Comparative \& Physiological Psy chology. $1959,52,408-410$.

MASTERSON, F. A. Is termination of a warning signal an effective reward for the rat? Journal of Comparative \& Physiological Psychology, 1970, 72 . $471-475$.

MEYER, D., CHO, D., \& WESEMANN, A

On problems of conditioning discriminated lever-press avoidance.
Psy chological Review, 1960,67, 224-228. MOWRER, O H \& LAMOREAUX, R, R.

Fear as an intervening variable in avoidance conditioning. Joumal of Comparative Psychology, 1946, 39, 29-50. 